\title{
Habermas Lendo Peirce
}

\author{
Lauro Frederico Barbosa da Silveira ${ }^{l}$
}

\begin{abstract}
RESUMO: Entre as várias referências feitas ao pensamento de Peirce, ao longo de sua carreira filosófica, dois textos foram tomados como exemplares da leitura que Jürgen Habermas faz do pensamento de Peirce e, ao lado das diferenças encontradas entre os dois textos, dois itens muito importantes se conservam: a verdadeira admiração pela virada pragmática promovida por aquele filósofo e cientista, que será seguida por seu leitor, e a séria restrição feita à progressiva tendência do pensamento de abandonar a intersubjetividade como garantia da objetividade da semiose, dando preferência a uma fundamentaçáo cosmológica para todo conhecimento. Embora esta última restrição pudesse ser criticada em sua pertinência, tanto a admiração manifesta à contribuição feita por Peirce ao pensamento filosófico com sua proposta pragmática, quanto a restrição a um suposto abandono das relaçōes pessoais na base da semiose, sem dúvida, manifestam o viés filosófico de Habermas lendo um autor que ele admira, mas que não pretende seguir como um exegeta.
\end{abstract}

PALAVRAS-CHAVE: Virada pragmática. Semiose. Intersubjetividade. Cosmologia.

Em "Peirce and Communication", Habermas inicia sua exposição fazendo a ressalva de que não pretende de modo algum assegurar ao leitor e, inicialmente ao ouvinte, estar dando conta da totalidade do pensamento peirciano, tarefa quase impossível para qualquer estudioso. Respeitados esses limites, os comentários que a seguir serão feitos à leitura de Peirce proposta em dois textos por Habermas procurarão avaliar o que pôde significar para o questionar filosófico deste último autor um pensamento que tanto o instiga.

\footnotetext{
${ }^{1}$ Professor no Programa de Pós-Graduação em Filosofia da UNESP - campus de Marília. E-mail : lfbsilv@terra.com.br

${ }^{2}$ HABERMAS, Jürgen. Peirce and Communication. In: KETNER, Kenneth Laine (Ed.). Peirce and Contemporary Thought. New York: Fordham University Press, 1995, p. 243-265.
} 
As leituras que serão aqui abordadas tiveram lugar em momentos distintos da trajetória intelectual de Habermas. A primeira data de obra editada em 1972 e será consultada em sua versão inglesa; trata-se de Knowledge and Human Interests ${ }^{3}$. A segunda resulta de uma apresentação oral realizada na Harvard University, em 1989, por ocasião do Sesquicentenário do nascimento de Peirce, tendo sido publicada, em 1995, sob o título acima já mencionado - "Peirce and Communication.” A importância conferida por Habermas ao pensamento de Peirce, reconhecendo-lhe o valor ou sobre ele exercendo enérgica crítica, pode ser verificada pela reiterada mençáo presente ao longo de toda evolução de seu pensamento. Isso se demonstra em estudos mais recentes de sua obra. ${ }^{4}$

Retendo-se, contudo, a presente leitura somente aos dois textos acima mencionados, e devido ao longo espaço de tempo que os separa, pareceu conveniente lê-los separadamente e somente na conclusão tentar-se encontrar certas características comuns que talvez sirvam para elucidar o modo como Habermas lê, ou vinha lendo, Peirce. Respeitando a ordem cronológica de suas publicaçôes, a atençáo se voltará primeiramente para Knowledge and Human Interests.

Naquele livro, uma passagem provavelmente sintetiza a questão que, salvo engano, percorre a preocupaçáo do autor: como se legitima o conhecimento científico da realidade. Desse modo, diz o texto:

Quais são as propriedades das condiçôes transcendentais de um processo de investigação em cujo enquadramento a realidade é objetivada de tal modo que apreendemos o geral no singular - isto é, que podemos inferir a validade das proposiçóes universais a partir de um número finito de casos singulares? A partir desta perspectiva transcendental ... dentro do enquadramento colocado com o processo de investigaçáo podemos constituir os objetos da experiência possível tais que a realidade se desdobre em uma constelação definida do universal e do particular. Esta constelaçáo pode ser demonstrada nos modos de inferência dos quais o progresso da investigaçáo logicamente depende. (HABERMAS, 1972, p. 111-112).

Ao não assumir qualquer instância que confira transcendentalidade à linguagem, Peirce só poderia sustentar que os universais são reais ao estabelecer

\footnotetext{
${ }^{3}$ HABERMAS, Jürgen. Knowledge and Human Interests. Transl. by Jeremy J. Shapiro. London: Heinemann, 1972.

${ }^{4}$ Entre os estudos mais recentes realizados no Brasil sobre o posicionamento de Habermas e Apel com referência ao pensamento de Peirce, considere-se o artigo da autoria de ZANETTI, José Luiz. Elementos de Peirce no debate entre Habermas e Apel. Cognitio vol. 9, n.1, São Paulo, EDUC, p. 125-152, jan/jun. 2008.
} 
um quadro categorial fundado na fenomenologia e, por consequência, num contexto empírico; ou adotaria alguma forma ingênua de ontologia - como, por exemplo, assumir ser a natureza um sujeito absoluto de que todas as representaçóes emanariam, ou submetendo o real à representação que dele seria feita, incorrer no erro lógico da petição de princípio: o conhecimento é real, pois o real encontra seu fundamento no conhecimento. Essa denúncia, colocando em nota um texto de Peirce que a justificaria, será enunciada do seguinte modo:

Caso assumamos que a realidade não se constitui independentemente das regras às quais está sujeito o processo de investigação, então não podemos nos referir a esta realidade para justificar as regras do processo de investigação, que são os modos de inferência. ${ }^{5}$

Habermas mostra-se convicto de que o móvel que levou Peirce a elaborar sua filosofia teria sido compreender o progresso da ciência. De tal modo esse empenho teria sido a meta de seu filosofar, que o alcance da verdade se apresentaria como resultado de um esforço coletivo. $\mathrm{Na}$ esperança de um tal sucesso, as formas sintéticas de juízo encontrariam sua validade e o método mais seguro de fixação da crença e de determinação do procedimento de se pensar quanto mais rigoroso fosse e mais sensível à resistência do experimento, melhor determinaria o conhecimento verdadeiro. O método pragmatista de conceituação, como previsão das consequências experimentais, consagraria essa concepção da validade, objetividade e verdade e legitimaria, nas palavras de Habemas (1972, p. 121) "[...] a validade dos modos sintéticos de inferência com base na estrutura transcendental da ação instrumental”.

No entanto, Peirce teria abandonado o estudo transcendental dessas condiçóes da experiência e passa a omitir no processo do conhecimento o papel do sujeito. Muito mais ainda, abandonaria a insubstituível consistência da subjetividade para reter-se na representação da estrita objetividade do experimento. O experimentador como "alguém" é substituído por "alguma coisa” atuante (HABERMAS, 1972, p. 132).

\footnotetext{
${ }^{5}$ Peirce não hesita ao expressar essa tautologia: "Como todo conhecimento vem da inferência sintética, devemos igualmente inferir que toda certeza consiste meramente em sabermos que os processos pelos quais nosso conhecimento derivou são tais que devem geralmente ter levado a conclusôes verdadeiras" ("Probability of Induction," PEIRCE, C. S. The Collected Papers of Charles S. Peirce, Vol.2 Edited by Charles Hartshorne and Paul Weiss. Cambridge MA: The Belknap Press of Harvard University. 1931/1976, \$693).
} 
A inserção do conhecimento no âmbito de uma inteligibilidade do cosmos, que poderia oferecer uma plausível razão para os acertos da ciência, recupera no texto peirciano a presença do instinto presente na raiz da vida e de toda a racionalidade. Essa conjectura peirciana leva Habermas dialeticamente a aprofundar sua própria exigência de procurar uma instância transcendental naquela obra. Contudo, não a encontra e, com isso, encontra mais uma razão para insistir no quase positivismo impessoal e radicalmente instrumental daquele pensamento.

Se a tendência assintótica rumo à verdade decorrente de uma lógica da investigação fosse, aos olhos de Habermas, seguida até suas últimas consequências, e o acordo último da comunidade dos investigadores, tão propalado por Peirce, fosse considerado em todas as suas exigências, o papel da intersubjetividade não poderia deixar de ser levado em conta e devidamente elaborado. Peirce, infelizmente, assim não procedeu e deixou em aberto condiçóes fundamentais para levar adiante uma investigação de grande envergadura.

No segundo texto escolhido para a presente leitura, a saber, "Peirce and Communication," o tema central da exposição sofre um certo deslocamento e, na fala de Habermas, trouxe consigo a dificuldade de ser um assunto aparentemente pouco tratado por Peirce. Em busca de indícios do tema na obra peirciana, Habermas, nos primeiros parágrafos de sua exposição, já se sente na obrigação de apontar uma certa estranheza quando Peirce se refere à comunicação. Definindo a evolução do pensamento como o desenvolvimento de uma forma dialógica (CP $4 . \$ 551)^{6}$, Peirce, em vez de mencionar falante e ouvinte, refere-se a uma só mente, composta de duas quase-mentes: a do enunciador e a do intérprete.

Como bom dialético e respeitando o contexto de estar falando num congresso dedicado à obra de Peirce, Habermas trata logo de justificar a opção peirciana, naquela substituição, ter ela decorrido do intento de tratar o pensamento na sua maior amplitude e evitar de restringi-lo à experiência exclusivamente humana. Muito especialmente, Peirce não pretendia confundir semiose e linguística, mas dar conta de toda e qualquer espécie de signo, ou, como dirá Habermas (1972, p. 244) mais adiante, buscar o signo elementar, condição necessária para qualquer signo.

${ }^{6}$ PEIRCE, C. S. The Collected Papers of Charles S. Peirce, Vol.4 Edited by Charles Hartshorne and Paul Weiss. Cambridge MA: The Belknap Press of Harvard University, 1931/1976. 
Essa manifesta compreensão da natureza do projeto peirciano não irá, contudo, eximir Habermas de apontar as consequências da ausência da consideração da intersubjetividade inerente ao processo comunicativo. Tal ausência mais grave parece ser devido ao fato de decorrer do abandono progressivo por parte de Peirce que, de início, muito se interessou pelas correlaçóes entre os três componentes dos processo comunicativos, ou seja, o Eu, o Tu e o Ele, para se restringir à função mental implicada na semiose.

Após apresentar esse contexto, Habermas (1972, p. 247) apresentará seu programa de exposição e dirá:

Agora, a questáo que me interessa é: Quais consideraçóes poderiam ter levado Peirce a se afastar dos aspectos intersubjetivos do processo de signos? Quero defender a tese de que é impossível fornecer uma explicação satisfatória da relação interpretante do signo sem recorrer às condiçóes para se alcançar um acordo intersubjetivo, por mais rudimentar que ele possa ser. Isto permanece impossível sempre que se conceber uma representação mediada por signos, tal como Peirce a concebeu, em termos de verdade e realidade - pois estes conceitos se referem por sua vez à idéia reguladora de uma comunidade de investigadores que opera sob condiçōes ideais. $\mathrm{Na}$ medida em que Peirce não se afastou de sua intuição principal, de que a virada pragmática não pode ser consistentemente levada adiante sem que se aceite estas pressuposiçóes contra-fatuais, ele não poderia proceder sem uma semiótica com bases intersubjetivas.

Para bem fundamentar sua tese, Habermas irá expor as contribuiçôes que julga ter Peirce trazido à filosofia.

O âmago do reconhecimento por parte de Habermas da contribuição de Peirce à filosofia, reconhecimento este que Habermas já encontra da obra de Karl-Otto Apel ${ }^{7}$, é a assim chamada virada especificamente pragmática e que, por razóes de brevidade, pode se resumir na seguinte citaçáo:

Depois da virada pragmática, contudo, a verdade de um signo sentencial deve ser medida tanto face à sua relaçáo de objeto como face a razóes que poderiam ser aceitas para sua validade por uma comunidade interpretativa. Assim, no novo paradigma, o papel do sujeito é assumido não pela linguagem per se, mas pela comunicaçáo entre aqueles que demandam

\footnotetext{
${ }^{7}$ APEL, Karl-Otto. Der Denkweg Von Charles Sanders Peirce. Eine Einführung in den amerikanischen Pragmatismus. Franklfurt am Main: Suhrkamp Taschenbuch, 1967-1970.
} 
explicaçóes uns dos outros a fim de alcançar um acordo razoável a respeito de alguma coisa no mundo. ${ }^{8}$

De uma filosofia centrada na consciência, abre-se para uma filosofia que se desenvolverá em torno e a partir das relaçóes comunicativas.

Se este é o preito prestado a Peirce e que torna seu pensamento objeto necessário de reflexão filosófica, não exime o leitor de assumir uma posição crítica, exatamente para dar prosseguimento ao trabalho tão duramente começado. Habermas, então, irá dedicar a parte mais substancial de sua comunicação para traçar as críticas que julga deverem ser feitas ao pensamento peirciano.

À questão da possibilidade de uma experiência dotada de objetividade para uma mente irredutivelmente semiótica, presa a "discursos e práticas" e ligada "a cadeia de signos", Habermas encaminha a possível resposta de Peirce, tomando por base três considerações.

Em primeiro lugar, os signos para Peirce cobrem um espectro muito mais amplo do que os signos linguísticos, a classe dos signos simbólicos e mesmo a de todos os signos convencionais e, portanto, disputáveis em sua formação e significado.

Em segundo lugar, não mais considerando a extensão da classe dos signos, mas a profundidade de sua gênese, Peirce náo irá escamotear o problema, mas irá reconhecer que, mesmo no limiar dos processos conscientes, os perceptos na forma dos juizos perceptivos já assumem um caráter semiótico e, por conseguinte, inferências falíveis, embora indubitáveis. Portanto, mantendo-se falíveis, não bastarão eles, na interpretação de Habermas, para garantir a total objetividade da experiência. Peirce teria, pois, buscado no "modo de processar informação o que irá garantir a verdade."A mente é dotada de uma lógica instintiva - uma lógica utens - para proceder a inferências sintéticas, como inferências sobre os fatos, sendo elas eminentemente úteis à vida. Projetada no âmbito da própria natureza a todos envolvente, essa lógica seria compartilhada por todos e, através de confrontos e discussóes, iria corrigindo aos poucos suas inferências sobre o real. A garantia da objetividade do conhecimento, como aproximação em direção à verdade, se daria no contexto dialético, se este for entendido no sentido clássico do termo.

${ }^{8}$ APEL, Karl-Otto. Charles S. Peirce. From Pragmatism to Pragmaticism. Translated by John Michael Krois. Amherst MA: University of Massachusetts Press, 1981, p. 250. 
Em terceiro lugar, mas não menos importante, Peirce insistiu na contraprova do experimento. Se todo empenho do conhecimento é fixar uma crença de como interagir com a realidade e, com isso, alcançar a verdade, a fundamentação dessa crença provou-se frágil sempre que tomou essas próprias crenças como seu fundamento. Fossem as convicçóes individuais de quem crê, fossem as doutrinas das autoridades, fosse, mesmo, a pretensão de se postular, por via da intuição, as formas sintéticas a priori da razão, todas elas se manifestam sujeitas à fragilidade exatamente por serem dependentes das opções subjetivas, objeto da própria dúvida e da insegurança dela decorrente. Somente um método de se avaliar as representaçóes pela experimentação com os objetos poderia corrigir-se em seus erros e se encaminhar rumo à verdade.

Essa tese, apresentada por Peirce nos anos de 1877 e 1878, nos artigos "The Fixation of Belief” e "How to make our Ideas clear" (CP 5. \$\$ 358-387; $\$ \$ 388-410^{\circ}$ ), é parcialmente contestada por Habermas, devido ao fato de exigir também a criação de um espaço intersubjetivo entre os intérpretes. E, assim, dirá:

A objetividade da experiência não é possível sem a intersubjetividade envolvida para se chegar "ao entendimento inicial" pois, como dirá mais adiante " as regras de inferência não podem por elas mesmas gerar resultados que possam compelir, e assim não podem ser reproduzidos no nível semântico como algoritmos. O processamento argumentativo da informaçáo tem que assumir a forma de uma prática intersubjetiva. (HABERMAS, 1972, p. 256-257).

E a própria intersubjetividade, que implicitamente poderia ser encontrada na argumentação peirciana, não seria, aos olhos de Habermas (1972, p. 257), suficiente para atender a essa exigência de garantir universalmente a objetividade do conhecimento. Seria necessário reconhecê-la como instância transcendental, para que assim o fizesse. $\mathrm{Na}$ dependência histórica como uma realidade empírica, essa intersubjetividade continuaria dependente de condiçôes particulares, somente garantindo uma crença subjetiva.

O dilema constituído entre semiose e realidade náo teria escapado à atenção de Peirce, dado o risco de reduzir a realidade à sua representação. Segundo Habermas, porém, a solução procurada por Peirce o distanciou mais ainda de uma abordagem que efetivamente o encaminharia para uma compreensão mais concreta do problema.

${ }^{9}$ PEIRCE, C. S. The Collected Papers of Charles S. Peirce, Vol.5. Edited by Charles Hartshorne and Paul Weiss. Cambridge MA: The Belknap Press of Harvard University. 1931/1976. 
Em vez de se dirigir para desvendar as implicações de ação comunicativa, Peirce teria preferido voltar-se a uma origem cósmica comum a todos os seres, moldando esse cosmos para a Lei da Mente e descobrindo, mesmo que meritoriamente, em todas as esferas do real, relações semióticas. Aos olhos de Habermas, a insuficiência da solução da objetividade da representação do real permaneceria intacta.

Quanto mais a solução é buscada em nível cósmico, mais se esvaziaria no texto peirciano a efetiva e insubstituível interação entre pessoas dotadas de individualidade, trocando suas interpretaçóes por via da linguagem e procurando histórica mas transcendentalmente um consenso final.

Reiterando seu respeito ao trabalho desse grande pensador, devolve a Peirce, para concluir, a crítica que aquele fizera a Hegel: evitar o embate insuperável de individualidades para procurar uma esfera totalizando uma racionalidade não estritamente transcendental sendo, contudo, transcendente.

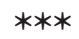

Após esta simples leitura, crê-se que alguma pequena conclusão poderia ser buscada. Náo seria difícil encontrar textos de Peirce que se contrapusessem às principais críticas apresentadas por Habermas, em ambos os textos aqui contemplados. Peirce jamais deixou de considerar a semiose e, com ela, todo o pensamento como um profundo diálogo entre pessoas em vista de um bem, preferivelmente procurado com todos os homens. Também não eliminou a figura do intérprete sujeito do pensamento para substituí-lo por uma mente interpretante. Simplesmente tratava-se de proceder a análises em níveis diferentes de abordagem: um mais próximo das situaçóes específicas da conduta humana e o outro propositadamente abstrato para cobrir hipoteticamente, como devem ser todos os signos para uma inteligência capaz de aprender através da experiência. Da situação humana não custa lembrar, por exemplo, que ele coloca como condição real do experimento o cientista de carne e osso (em inglês, "flesh and blood"), interagindo como os instrumentos de trabalho em sua bancada de químico, que efetivamente ele o era, quando diz que o químico pensa com as pontas dos dedos ou quando também diz que se pensa tanto com o cérebro quanto com a tinta da caneta e, muito mais ainda, quando irá dizer que os exemplos eminentes da razoabilidade ("reasonableness") são o afeto 
da mãe pelo seu bebê ou a fidelidade do amigo. Dessa razoabilidade, convém lembrar, Peirce valoriza antes de tudo o afetivo, do qual não só os humanos mas múltiplos seres participam, reservando o racional, predominante lógico, a determinadas funçôes de grande importância mas nem sempre tão necessárias à manutenção da vida e ao brotar da personalidade.

Seria oportuno, também, modalizar aquela afirmação presente em Knowledge and Human Interests, de que o sucesso da ciência teria sido o grande móvel da investigação filosófica de Peirce. A posição de Peirce diante de um progresso do pensamento e, em especial, da ciência, certamente jamais foi de um otimismo ingênuo. Sem descrer na ciência ou na razão, Peirce as teve como intrinsecamente falíveis e, se em algum momento alcançaram a verdade, ou de fato progrediram para alcançá-la, isso sempre se deu e se dará de modo intrinsecamente falível e "de modo algum necessário"! A opinião futura da comunidade dos investigadores, quando a Verdade absoluta seria alcançada, sequer implicava para Peirce reconhecê-la como instância transcendental. Quem determina a verdade é o confronto de nossas expectativas eminentemente falíveis com o objeto de tais expectativas, e tal confronto mais serve para apontar erros do que para confirmar verdades. Erros de conduta e não de teses, pois a lógica para Peirce está por sua própria natureza submissa à ética e esta, à estética, ciência do admirável de tudo que aparece. Fica aberta a possibilidade de se entender a crença da comunidade futura que já vem se constituindo ao longo do tempo, por sua natureza última, ou seja, quando e onde sua crença não encontrar objetos que a elas resistam, porque só eles são o critério de validade das representaçóes e a razão de se pensar, sendo somente eles admiráveis e queridos como bem.

Todavia, não parece ser oportuno multiplicarem-se estas contraposiçóes. O mais importante seria tentar-se compreender o próprio sentido da leitura feita por alguém tão admirável quanto Habermas. Nele, encontra-se o exemplo de um pensador: alguém que pensa, pondera, pesa as ideias e as confronta com as de outros pensadores, estabelecendo um diálogo frequentemente ríspido e provisoriamente parcial, senão até injusto.

Não se trata, por conseguinte, da postura do comentador que procura deslindar o texto e sistematizar as ideias com total preocupação com a integridade e a integralidade do pensamento que pretende elucidar. No diálogo, o risco de possíveis enganos são plenamente compensados, pois instigam a investigação da comunidade dos interlocutores. Publicada a obra, essa comunidade cresce indefinidamente em rede. 
Finalmente, os textos de Habermas, quando tomam Peirce com interlocutor, caracterizam o posicionamento de um filósofo de tradição alemã, lendo um autor que, embora cosmopolita em sua cultura, responde aos questionamentos da tradição anglo-saxã. $\mathrm{O}$ respeito de Habermas pelo pensamento de Peirce será plenamente autêntico, quando o desafia com questôes que não serão literalmente respondidas, mas que calarão na mente de quem pergunta, como um incentivo a que continue a pesquisar, encontrando naquele pensamento estrangeiro, quem sabe, afinidades escondidas que os pensamentos compatriotas não seriam capazes de trazer à luz.

SILVEIRA, Lauro Frederico Barbosa. Habermas Reading Peirce. Trans/Form/Ação, Marília, v. 36, p. 33-44, 2013. Edição Especial.

\begin{abstract}
Among several references made to Peirce's thought during Jürgen Habermas' philosophical career, two texts are exemplars of the reading Habermas makes of Peirce's thought. Despite the differences found between the two texts, two very important items are conserved: a true admiration for the pragmatic turn promoted Peirce (and followed by Habermas), and serious restrictions with regard to the progressive tendency in Peirce's thought toward abandoning intersubjectivity as the warrant of the objectivity of semiosis and giving preference to a cosmological foundation to all kinds of knowledge. Although this last restriction could be criticized as to its pertinence, both the admiration manifested by Habermas for Peirce's contribution to philosophical thought in his pragmatic proposal, as well as Habermas's restrictions regarding a supposed abandonment of personal relations on the basis of semiosis, undoubtedly manifest the philosophical bias of Habermas' reading of an author he admires but does not intend to follow as an exegete.
\end{abstract}

KEYWORDS: Pragmatic turn. Semiosis. Inter-Subjectivity. Cosmology.

\title{
REFERÊNCIAS
}

APEL, Karl-Otto. Der Denkweg Von Charles Sanders Peirce. Eine Einführung in den amerikanischen Pragmatismus. Franklfurt am Main: Suhrkamp Taschenbuch, 1967-1970.

APEL, Karl-Otto. Charles S. Peirce. From Pragmatism to Pragmaticism. Translated by John Michael Krois. Amherst MA: University of Massachusetts Press, 1981.

HABERMAS, Jürgen. Peirce and Communication. In: KETNER, Kenneth Laine (Ed.). Peirce and Contemporary Thought. New York: Fordham University Press, 1995, p. 243-265.

HABERMAS, Jürgen. Knowledge and Human Interests. Transl. by Jeremy J. Shapiro. London: Heinemann, 1972. 
PEIRCE, C. S. The Collected Papers of Charles S. Peirce, Vol.2 Edited by Charles Hartshorne and Paul Weiss. Cambridge MA: The Belknap Press of Harvard University, 1931/1976.

PEIRCE, C. S. The Collected Papers of Charles S. Peirce, Vol.4. Edited by Charles Hartshorne and Paul Weiss. Cambridge MA: The Belknap Press of Harvard University, 1931/1976.

PEIRCE, C. S. - The Collected Papers of Charles S. Peirce, Vol.5. Edited by Charles Hartshorne and Paul Weiss. Cambridge MA: The Belknap Press of Harvard University, $1931 / 1976$.

ZANETTI, José Luiz. Elementos de Peirce no debate entre Habermas e Apel. Cognitio vol. 9, n.1, São Paulo, EDUC. p. 125-152, jan/jun. 2008. 
SILVEIRA, L. F. B. 